\title{
Neurofibroma and Pectoralis Muscle Hypoplasia: A Mild Degree of Poland's Syndrome
}

\author{
Caiping Chen Jianju Lu Xiang Lu Wanxin Wu Wenlan Han \\ Department of Breast Surgery, The First Affiliated Hospital, College of Medicine, Jiaxing College, Jiaxing, P. R. China
}

\section{Keywords}

Neurofibroma · Poland's Syndrome · Gynecomastia

\section{Summary}

Background: Poland's Syndrome (PS) is a rare congenital syndrome characterized by the unilateral partial or complete absence of the sternocostal head of the pectoralis major muscle and ipsilateral brachysyndactyly or syndactyly of the fingers. It has been reported to be associated with other diseases, but PS accompanied by neurofibroma has rarely been reported. Case Report: We report a rare case of a 16-year-old man with neurofibroma of the left breast accompanied by PS. Physical examination showed a mass in the left breast with skin hyperpigmentation and increased body hair. Intraoperative exploration showed a mass measuring $3-4 \mathrm{~cm}$ between the dysplastic pectoralis major and minor muscles. Pathologic examination of the resected mass showed cutaneous diffuse neurofibroma. A simple left mastectomy was performed. The postoperative course was uneventful with no evidence of recurrence at 4 months. Conclusion: Neurofibroma may also be accompanied by PS and should be differentiated from gynecomastia when a tumor grows in the breast.

\section{Introduction}

Poland's syndrome (PS) is a rare congenital syndrome characterized by the unilateral partial or complete absence of the sternocostal head of the pectoral major muscle and ipsilateral brachysyndactyly or syndactyly of the fingers. Other common anomalies in conjunction with PS include malformations of

\author{
Schlüsselwörter \\ Neurofibrom · Poland-Syndrom · Gynekomastie
}

\section{Zusammenfassung}

Hintergrund: Das Poland-Syndrom (PS) ist eine seltene Erbkrankheit, die mit dem einseitigen teilweisen oder vollständigen Fehlen des sternokostalen Kopfes des Musculus pectoralis major sowie ipsilateraler Brachysyndaktylie oder Syndaktylie der Finger einhergeht. Assoziationen mit anderen Erkrankungen sind bekannt. Über PS in Verbindung mit Neurofibromen ist bisher jedoch nur selten berichtet worden. Fallbericht: Wir berichten den seltenen Fall eines 16-jährigen männlichen Patienten mit einem Neurofibrom der linken Brust begleitet von PS. Die körperliche Untersuchung ergab eine Umfangsvermehrung in der linken Brust mit Hyperpigmentierung der Haut und vermehrter Körperbehaarung. Die intraoperative Untersuchung zeigte einen 3-4 cm großen Knoten zwischen dem dysplastischen Musculus pectoralis major und dem ebenfalls dysplastischen Musculus pectoralis minor. Die pathologische Untersuchung des resezierten Tumors ergab ein diffuses kutanes Neurofibrom. Eine einfache linksseitige Mastektomie wurde durchgeführt. Der postoperative Verlauf war unauffällig, und nach 4 Monaten bestanden keine Anzeichen eines Rezidivs. Schlussfolgerung: Neurofibrome können mit PS einhergehen und sollten bei bestehenden progressiven Umfangsvermehrungen in der Brust von Gynekomastie unterschieden werden.

the anterior chest wall and breast, absence of the pectoral minor muscle, and dextrocardia $[1,2]$. The incidence of PS is reported to be approximately $1: 30,000$, with a higher frequency among males [3]. Here we present a rare case in which the only clinical expression was dysplasia of the left pectoralis major and minor muscles, accompanied by neurofibroma on the same side.

\section{KARGER \\ Fax +49 7614520714 \\ Information@Karger.de}

www.karger.com (c) 2012 S. Karger GmbH, Freiburg

1661-3791/12/0076-0490\$38.00/0

Accessible online at:

www.karger.com/brc
Caiping Chen, MD

The First Affiliated Hospital

College of Medicine; Jiaxing Colleg

No. 1882 Zhonghuan South Road

Jiaxing 314000, P. R. China

jjadf@zju.edu.cn 

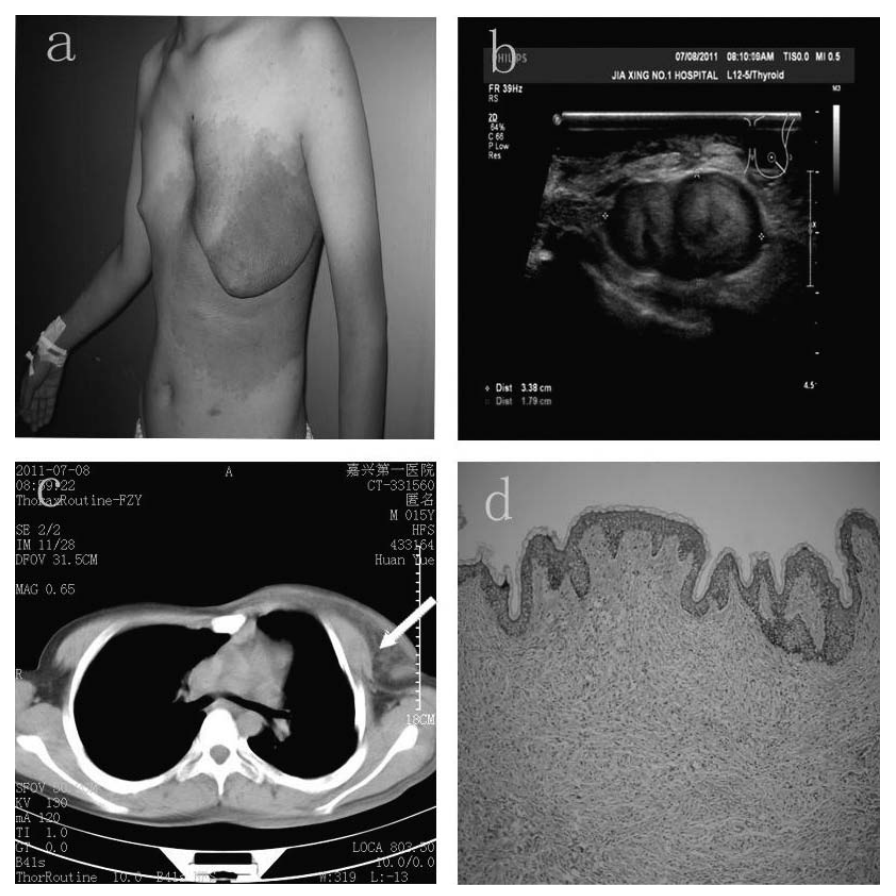

Fig. 1. a Deformity of the chest wall and significant hypertrophy of the left breast. b Ultrasound showing a low-echo mass in the left breast. c Axial thoracic computed tomography scan revealing deformity of the chest wall and a mass in the left breast (white arrow). d Pathologic examination showing cutaneous diffuse neurofibroma, involving the skin and subcutaneous tissue $(\mathrm{H} \& \mathrm{E} \times 100)$.

\section{Case Report}

A 16-year-old Chinese man was admitted to our hospital in July 2011 complaining of a breast mass. He was born with a small nodule in his left breast which was growing slowly and was not associated with pain or any other symptoms. Findings from the physical examination revealed deformity of the chest wall, increased body hair, and significant hypertrophy of the left breast with skin hyperpigmentation (fig. 1 a). Palpation of the left breast showed a 3-4 cm, non-tender, freely mobile mass with clear boundaries. No palpable lymph nodes were detected. Breast ultrasound examination showed a mass in the left breast with low echo (fig. $1 \mathrm{~b}$ ), and abdominal ultrasound showed mild splenomegaly. Computed tomography (CT) showed deformity of the chest wall and a mass in the left breast (fig. $1 \mathrm{c}$ ). Inflammation of the lower lobe of the left lung was noted. Laboratory tests, including complete blood count, liver function tests and tumor markers, were all normal. There was no relevant medical or family history. The patient underwent a simple left mastectomy. During surgery, we found that the left pectoralis major and minor muscles were significantly hypoplastic. Intraoperative pathological examination of the mass revealed a neurofibroma. The pathological result was further confirmed by the Fudan University Shanghai Cancer Center as cutaneous diffuse neurofibroma. The pathological changes involving the entire specimen including skin and subcutaneous tissue are shown in figure $1 \mathrm{~d}$. Some immunohistochemical indexes were detected: S-100+, CD34+/-, Desmin-, SMA-. On the basis of the above findings, a mild degree of PS accompanied by neurofibroma was diagnosed. There were no typical symptoms such as brachydactyly or syndactyly in this case. The postoperative course was uneventful, and there was no evidence of recurrence of the neurofibroma during the 4-month follow-up.

\section{Discussion}

PS is a rare congenital disorder characterized by hypoplasia of the pectoral muscles along with upper extremity deformities. Besides, other manifestations including hypoplasia or absence of the breast and nipple-areola complex, abnormalities of the anterior ribs, clavicle and scapula, lung herniation, renal agenesis, and dextrocardia may also exist $[2,4,5]$. More than $75 \%$ of the defects associated with this syndrome are present on the right side [6]. PS has also been reported to be associated with Moebius syndrome and Pierre Robin syndrome $[7,8]$, leukemia and non-Hodgkin's lymphoma [9, 10], and hemangioma [11]. The etiology of PS is most likely due to an interruption of the embryonic blood supply in the subclavian artery during the 6th week of gestation [12]. Besides thrombi or thrombotic emboli within the placenta have also been suggested as a cause of PS [4]. However, the exact etiology and pathogenic mechanisms are still unknown.

PS accompanied by neurofibroma has rarely been reported thus far. In 1994, Alembik et al. [13] first reported on a boy with neurofibromatosis 1 and Poland's anomaly, and there have been no similar reports since. Hence, more cases of PS accompanied by neurofibroma would have to be reported in order to confirm neurofibroma as part or a variation of PS. Here, we report on a patient with a mass in his left breast accompanied by skin hyperpigmentation and increased body hair. The left pectoralis major and minor muscles were both significantly dysplastic. The patient underwent a simple left mastectomy, and pathologic examination of the surgical specimen showed cutaneous diffuse neurofibroma. PS is usually considered to be a hypoplasia of the pectoral muscles along with upper extremity deformities. However, in our patient, the only manifestation was dysplasia of the left pectoralis major and minor muscles. So is PS the correct diagnosis? There is a lack of literature further describing such patients. David TJ [14] reported 78 cases of congenital absence of the pectoralis major muscle, of which 46 cases met the diagnostic criteria of PS, and the remaining 32 cases were just isolated pectoralis absence without any other similar or related malformations [14]. So could the remaining 32 cases also be diagnosed as PS?

In 1989, Darian et al. [4] described a family in which 3 women had absence of the pectoralis major muscle and 2 men had hypoplasia or agenesis of the pectoralis major muscle. Although this feature was felt to be consistent with PS, none of the family members had upper limb abnormalities. However, this case was considered as familial PS. Other cases have also been reported in which the chest wall defect was not accompanied by any limb abnormalities [15]. Furthermore, Perez Aznar et al. [16] considered that hypoplasia of 1 breast or a horizontal anterior axillary fold may be the sole clinical manifestation of this syndrome. Thus, we believe that the manifestation of PS varies from person to person, and some patients may only have 1 clinical manifestation repre- 
sentative of a mild degree of PS such as in our patient. The main differential diagnoses are gynecomastia and breast cancer in this case. We first diagnosed this patient as gynecomastia, but the final pathological results rejected the primary diagnosis. As was reported, breast cancer may also be associated with PS [17]. In this case, there was no sign of malignancy of the mass, and the pathological results also excluded breast cancer.

Neurofibroma is a common benign tumor which arises from the epineurium of the peripheral nerve system. Because some patients with neurofibromatosis 1 (incidence approximately 1:4,000 [18]) may also manifest as solitary neurofibroma early on, it is difficult to get accurate statistics about the incidence of solitary neurofibroma. To the best of our knowledge, the vast majority of neurofibromas occur in the dermis or subcutis and are rarely detected in the breast tissue itself. The most common location in the breast is the areolar area $[19,20]$. Excluding the occurrence of neurofibroma in the presence of neurofibromatosis 1 which is regarded as a separate disease process, solitary neurofibroma of the breast is rare, especially in men [21], and currently there are only sporadic reports. Solitary neurofibroma is generally asymptomatic, grows slowly, and may increase faster at certain times such as puberty or pregnancy, which may lead to deformity, dysfunction, local tenderness, or paresthesia. Treatment of neurofibromas is usually by surgical excision. Because of recurrence and malignant tendency in some cases, postoperative follow-up is necessary.
For this male patient, we performed a simple left mastectomy only, but for a female patient reconstructive surgery after mastectomy should be considered. It has been reported that the use of an omental flap to reconstruct the breast can improve the esthetic outcome better than any other option [22]. It was also reported that transfer of the insertion of the latissimus dorsi muscle can improve the axillary fold deformity in male patients [23]. Recently, Yang et al. [24] reported on reconstructing deformities of a PS patient using autologous fat tissue, and the authors found that a higher condensation of fat tissues achieved by squeezing centrifugation can improve the outcome, increase volume maintenance, and reduce complications.

The postoperative course in our case was uneventful with no evidence of recurrence during 4 months of follow-up. However, since neurofibroma has the potential of recurrence or malignant transformation, long-term follow-up should be carried out to provide more information about long-term effects. In conclusion, we here report a rare case of PS accompanied by neurofibroma which should be differentiated from gynecomastia if there is a growing tumor in the breast.

\section{Disclosure Statement}

The authors declare that they have no competing interests.

\section{References}

1 Ireland DC, Takayama N, Flatt AE: Poland's syndrome. J Bone Joint Surg Am 1976;58:52-8.

2 Lacorte D, Marsella M, Guerrini P: A case of Poland syndrome associated with dextroposition. Ital J Pediatr 2010;36:21.

3 Moir CR, Johnson CH: Poland's syndrome. Semin Pediatr Surg 2008;17:161-6

4 Darian VB, Argenta LC, Pasyk KA: Familial Poland's syndrome. Ann Plast Surg 1989;23:531-7.

5 Assadi FK, Salem M: Poland syndrome associated with renal agenesis. Pediatr Nephrol 2002;17:26971.

6 Lord MJ, Laurenzano KR, Hartmann RW Jr: Poland's syndrome. Clin Pediatr (Phila) 1990;29: 606-9.

7 Wood VE, Sandlin C: The hand in the Pierre Robin syndrome. J Hand Surg Am 1983;8:273-6.

8 Sugarman GI, Stark HH: Mobius syndrome with Poland's anomaly. J Med Genet 1973;10:192-6.

$\checkmark$ Nachnani JS, Supe AN: A variant of Poland syndrome. J Postgrad Med 2001;47:131-2.

10 Costa R, Afonso E, et al.: Poland's syndrome associated with chronic granulocytic leukemia. Sangre (Barc) 1991;36:417-8.
Riyaz N, Riyaz A: Poland syndrome (anomaly) with congenital hemangioma: a new association. Indian J Dermatol Venereol Leprol 2006;72:222-3.

12 Shamberger RC: Congenital chest wall deformities. Curr Probl Surg 1996;33:469-542.

13 Alembik Y, Stoll C: A boy with neurofibromatosis 1 and Poland anomaly. Genet Couns 1994;5:167-70.

14 David TJ: Familial Poland anomaly. J Med Genet 1982;19:293-6.

15 Castilla EE, Paz JE, Orioli IM: Pectoralis major muscle defect and Poland complex. Am J Med Genet 1979;4:263-9.

16 Perez Aznar JM, Urbano J, et al.: Breast and pectoralis muscle hypoplasia. A mild degree of Poland's syndrome. Acta Radiol 1996;37:759-62.

17 Wong TC, Lim J, Lim TC: A case of ductal carcinoma in situ of breast with Poland syndrome. Ann Acad Med Singapore 2004;33: 382-4.

18 Huson SM, Compston DA, et al.: A genetic study of von Recklinghausen neurofibromatosis in south east Wales. I. Prevalence, fitness, mutation rate, and effect of parental transmission on severity. J Med Genet 1989;26:704-11.
19 Fink D, Schneider C, et al: (Neurofibromatosis of the breast in a patient with Morbus von Recklinghausen). Gynakol Geburtshilfliche Rundsch 2000;40:47-9.

20 Sherman JE, Smith JW: Neurofibromas of the breast and nipple-areolar area. Ann Plast Surg 1981;7:302-7.

21 Jeyaretna DS, Oriolowo A, et al.: Solitary neurofibroma in the male breast. World J Surg Oncol 2007;5:23.

22 Dos Santos Costa S, et al.: Aesthetic improvements in Poland's syndrome treatment with omentum flap. Aesthetic Plast Surg 2010;34:634-9.

23 Seyfer AE, Icochea R, Graeber GM: Poland's anomaly. Natural history and long-term results of chest wall reconstruction in 33 patients. Ann Surg 1988;208:776-82.

24 Yang H, Lee H: Successful use of squeezed-fat grafts to correct a breast affected by Poland syndrome. Aesthetic Plast Surg 2011;35:418-25. 